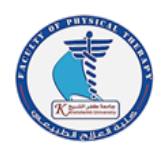

\title{
Photochemotherapy Versus Tap Water Iontophoresis For Management Of Atopic Dermatitis In Children
}

Hadaya M. Eladl ${ }^{1,2}$, Olfat I. Ali ${ }^{3,4}$, Mohamed A. Abdel Ghafar ${ }^{4}$, Rania R. Ali ${ }^{3}$, Riham AbdelMohsen Abdelsamie ${ }^{5}$, Ali Osman Selim ${ }^{1}$

${ }^{1}$ Department of Physical Therapy for Surgery, Faculty of Physical Therapy, Cairo University, Giza, Egypt.

${ }^{2}$ Department of Physical Therapy and Health Rehabilitation, College of Applied Medical Science, Jouf University, Jouf City, Saudi Arabia.

3 Department of Basic Science for Physical Therapy, Faculty of Physical Therapy, Cairo University, Giza, Egypt.

4 Physical Therapy Program, Batterjee Medical College, Jeddah, Saudi Arabia.

5 Department of Dermatology and Andrology, Faculty of Medicine, Benha University, Benha, Egypt.

*Correspondence to

Mohamed A. Abdel Ghafar, Physical Therapy Program, Batterjee Medical College, Jeddah, Saudi Arabia. Tel:00966531513909

Email;

pt12.jed@bmc.edu.sa

Published online:

Dec 2021

\begin{abstract}
:
Background: Atopic dermatitis is a long-term type of inflammation of the skin, it results in itchy, red swollen, and cracked skin. Clear fluid may come from the affected areas, which often thickens over time. While the condition may occur at any age, it typically starts in childhood, with changing severity over the years.

Objectives: to compare the effect of photochemotherapy versus tap-water iontophoresis for the management of atopic-dermatitis in children.

Methods: Fifty-six eligible children with atopic-dermatitis were randomlydesignated into three groups. Psoralen plus Ultra-Violet A (PUVA Group): $n=18$ received Bath-Psoralen, ultraviolet $A$ and traditional medical treatment three sessions per week for 8 weeks. (Iontophoresis Group): $n=18$ received tap-water iontophoresis and traditional medical treatment three sessions per week for 8 weeks. (Control group): $n=20$, received traditional medical treatment, applied twice daily for 8 consecutive weeks. Children were assessed using Patient Oriented Eczema Measure (POEM) Scale and Ultrasonography for skin thickness at baseline and at the end of 8 weeks of therapy.
\end{abstract}

Results: The three treatment approaches had significant effects in the management of atopic dermatitis in children based on the results of POAM scale and skin thickness ( $\mathrm{p}$ value< 0.05 ). Both of the study groups showed a significant improvement in comparison with the control group ( $\mathrm{p}$ value $<0.05)$. However, there was no significant difference between PUVA and iontophoresis groups ( $\mathrm{p}$ value $>0.05$ ).

Conclusion: This study deduced that adding photo-chemotherapy and tap-water iontophoresis to medical treatment proved to be superior to medical therapy only in improving the POEM scale and decreasing skin thickness in children atopicdermatitis.

Keywords: Photochemo-therapy, Tap water iontophoresis, atopic dermatitis, Bath psoralen, Skin Thickness. 


\section{Introduction}

Atopic dermatitis (AD) is a common chronic eczematous skin disease persisting predominantly in paediatrics. $\mathrm{AD}$ diagnoses are continuously on the rise, oscillating between $10 \%$ and $20 \%$ of the pediatric population. It is pervaded by a regression trail and marked overwhelming ramifications on quality of life as a public health problem. Onset of disease is most common by 5 years of age, and early diagnosis and treatment are essential to avoid complications of $\mathrm{AD}$ and improve quality of life (1).

Atopic dermatitis is a crucial medical and socioeconomic matter due to its high prevalence recently. The disease usually occurs in people with atopic tendency. It is usually associated with asthma, food allergies, rhinitis, and with high serum immunoglobulin E levels (2). The main problems in atopic dermatitis are uncontrollable itching and changed appearances. It may significantly impair the quality of life for both children and their families (3).

Management of $\mathrm{AD}$ is dominated by the application of topical glucocorticosteriods (4). That is when being not sufficient; Phototherapy is the next following plan in moderate and severe cases of $\mathrm{AD}$ that hinders coherently cutaneous inflammation with minimal or no complex adverse effects (5).

Photo-chemotherapy is a treatment approach depends on the advantageous ramifications of light waves on different pathological cases; it includes adding of psoralen to (UV) therapy that is known as PUVA, which is delivered through a fluorescent bulb. PUVA therapy is proved efficient with relatively few side effects (6). PUVA depends on the interactivity between UV radiation and a photosensitizing chemical. In the doses previously used, neither the radiation nor the chemical would have marked biologic results (7).

$\mathrm{AD}$ is an oppressive, persistent disease with inadequate therapeutic cures. PUVA appears as a conservative, advantageous cure in the therapy program, but it is not based on standardized routine indicating decision making for the optimum therapies for $\mathrm{AD}$ patients (8).

Iontophoresis is a non-invasive technique used for drug delivery by increasing the penetration of the skin in a controlled manner by applying electric currents. Recent technological breakthrough has provided low-cost equipment causing spreading of this therapeutical approach (9).
Sweat has been reported to trigger exacerbations in the itch-scratch cycle of atopic dermatitis. Surveys studies in China and the USA had suggested that $\mathrm{AD}$ patients usually consider sweat as the prime factor-triggering itching (10). The benefit of tap water iontophoresis in dealing with palmoplantar hyperhidrosis has been well proven leading to its extensive clinical application (11).

However, up to the authors knowledge there is insufficient research to compare the effect of phototherapy to the tap water iontophoresis in the treatment of atopic dermatitis in paediatrics. That is why further studies are needed to elucidate their effect. Therefore, the objective of our work was to compare the effect of phototherapy "psoralen and UVA" bath Psoralen to tap-water iontophoresis in the management of atopic dermatitis in paediatrics.

\section{Patients and Methods}

\subsection{Study design:}

A single-blinded, randomized controlled trial (only assessor) was conducted. Children were randomly assigned equally to PUVA and traditional medical treatment (PUVA group) or, tap water iontophoresis and the traditional medical treatment (Iontophoresis group) or traditional medical treatment (Control group). Randomization was conducted using computergenerated random tables, and sealed opaque envelopes were utilized for group allocation as shown in figure 1 .

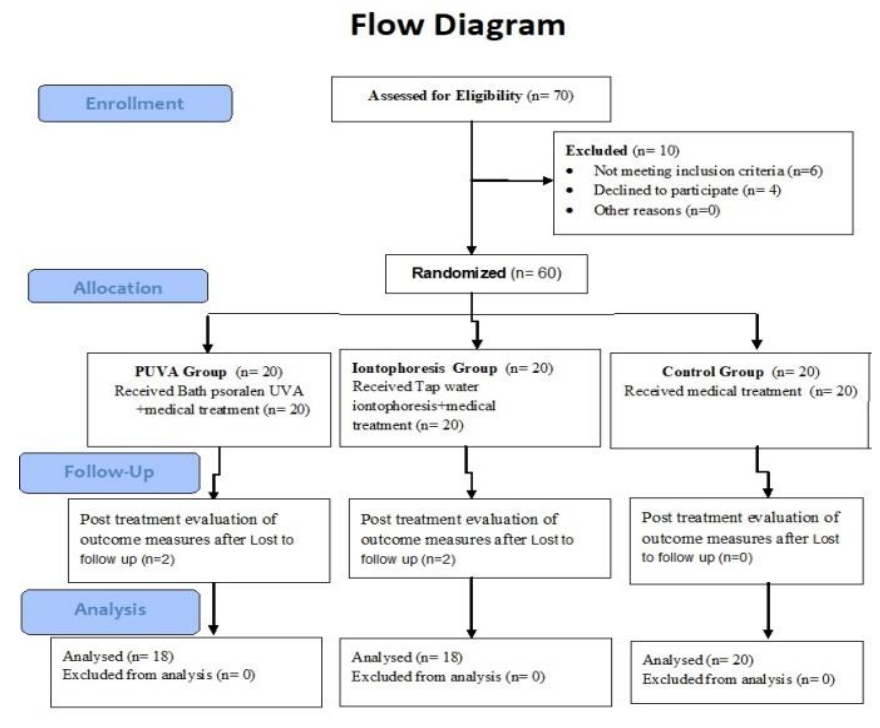

Figure (1): Flowchart for participant recruitment and allocation. 
Children with $\mathrm{AD}$ of the hands were sorted out from the department of dermatology, Banha Teaching Hospital, Al Qalyubia and Elmattaria Teaching Hospital, Cairo. The trial was regulated between January 2019 and November 2020. The faculty of physical therapy, Cairo University ethical committee approved the study (P.T.REC/012/002746). The children and their parents were illuminated in details about the type, purpose, and gains of the study, and signed a written informed consent template prior to the trial. The trial was prospectively registered at the clinical trial registry (NCT04444726). All children were diagnosed with atopic dermatitis of dyshidrotic type with hand eczema, were examined carefully for their eligibility to participate in the study by a dermatologist.

\subsection{Participants:}

Participants with dyshidrotic AD were recruited in this study according to the inclusion criteria of being between the age of 12 to 16 years, of both genders, being more than 6-months duration since the onset of the disease, in which traditional types of treatment options, including oral or topical corticosteroids had been proved ineffective. Children were excluded from this study if they had one of the following criteria: previous intolerance history to UV radiation, psoriasis, fungal infections, skin malignancy or acute infection at the area to be treated, children received radiotherapy in the area to be treated during the last 6 months, children received corticosteroid therapy topically within 14 days before treatment, or systemic corticosteroids or any immunosuppressive drugs within the last 4 weeks, circulatory and sensory disorders.

\subsection{Sample size calculation:}

The study sample size was calculated using G power software (Universities, Dusseldorf, Germany) with power 95\%, p value 0.05 and the effect size 0.5. Sample size was 17 participants in each group. In order to account for the dropout rate; sample size was 60 participants in the three groups.

\subsection{Outcome measures:}

The primary outcome measure of the study was the Patient-Oriented Eczema Measure "POEM", the secondary outcome measure was the thickness of the skin measured by ultrasonography. The entire assessments were applied by one of the authors before and after 8 weeks of treatment.
2.5. Patient-Oriented Eczema Measure (POEM) scale: The prime outcome measure for determining the effect of treatment was Patient-Oriented Eczema Measure (POEM). The scale is simple, valid, repeatable, and readily understandable tool for monitoring disease severity in children and adults with $\mathrm{AD}$. The degree of severity was estimated by asking young children to answer the questionnaire with the help of their parents (12). The POEM includes 7 questions regarding the number of days each symptom appeared. All questions are based on 5-point severity scales, with a total score ranging from 0 (lower severity) to 28 (higher severity); severity groupings have been defined as bands of 0 to 7 indicating mild $\mathrm{AD}, 8$ to 16 moderate $\mathrm{AD}$, and greater than 16 severe AD. The degree of severity was estimated by asking young children to answer the questionnaire with the help of their parents (12).

2.6. Thickness of the skin measured by Ultrasonography:

Assessment of the skin thickness was performed using the high frequency skin ultrasonography (Derma Scan Cortex Technology, version 3, Hadsund, Germany) the ultrasonography 7.5 $\mathrm{MHz}$, the ultrasound imaging system was used to measure the thickness of the skin at the affected site. Measurements were done under standardized conditions; measurements were carried out by the same investigator, all values were given as the mean of three recordings to avoid measuring inaccuracies, the same area was measured before and after therapy for each patient by determining it in relation to any landmark. The participants were informed not to apply any topical drugs at the night before the session. Before measurement, all children were given 10 minutes to adapt the room conditions. The thickness of the ultrasound coupling gel layer was adjusted to about $1 \mathrm{~mm}$ to ensure standardization, the area to be investigated was cleaned by the alcohol before application. The scan was obtained and transferred to the monitor screen where it could be obtained by the investigator and the instrument, then, a printed copy of the scan was done for documentation and referral purposes (13). Assessment was performed before then after 8 weeks of treatment for the three groups.

\subsection{Intervention:}

The participants at both study and control groups obtained identical medical treatment. 
Betamethasone dipropionate $0.05 \%$ "betamethasone" cream thin film was applied to the affected area for 2 times a day for 8 weeks. Pre-treatment preparation was performed including cleaning then rinsing of the treatment area with water and soap followed by a soft cloth to dry the skin surface $(14,15)$.

Patients in the "PUVA group" received Photochemotherapy (bath Psoralen). The patient's affected hand was socked for 20 minutes in "Methoxy Psoralen solution" $(30 \mathrm{ml}$ of 8methoxypsoralen $\quad 1.2 \quad \% \quad$ lotion (PUVASORALEN) in $140 \mathrm{~L}$ water (concentration of $2.6 \mathrm{mg} / \mathrm{L}$ ). Then the patient's hand was immediately irradiated by the Ultraviolet A device "Waldmann, Ultraviolet A: UV 181, 03781-0, U: 230 V, F: 50HZ., L: 1.2,2,413,7, Cos: 0.93, $0.79,0.7,2 \mathrm{XT}: 6.3 \mathrm{H}, 250$ v. ", Germany. The preliminary dose was $0.5 \mathrm{~J} / \mathrm{cm}^{2}$ UVA. Subsequent increase of $0.5 \mathrm{~J} / \mathrm{cm}^{2}$ UVA was performed after every third treatment session. All patients wore protective eye and face wear during therapy $(16,17)$.

Treatment was provided for 3 sessions per week for 8 consecutive weeks, in addition to the traditional medical treatment. All the safety measures were followed during the treatment. After each session and before the beginning of the successive session, the side effects were noted. All patients used photoprotective eye goggles before starting radiation. Participants were advised to protect themselves from sunlight throughout the treatment period (18).

Patients at the "Iontophoresis group" received tap water iontophoresis, Hidrex® (GS Hidrex GmbH, Wuppertal, Germany), 3 sessions /week, for 8 weeks, with the affected hand on the anode. The intensity was increased according to the patient's tolerance. The maximum level was $30 \mathrm{~mA}$ for 20 minutes. Before the treatment procedures, patients were asked to remove any metallic pieces (jewellery, watches). Cotton towel was used to cover electrodes to avoid direct skin contact. Skin erosions were covered with petrolatum or insulating tapes or wrappings. Tap water is poured in pans so that the patient's hands were covered up to the dorsal areas of hand (19).

\section{Data analysis:}

Measured outcomes (POAM and ultrasonography) were inspected for normality by checking data distribution. Measured parameters indicated a parametric distribution. So, Two-way mixed model MANOVA was applied to compare within and between measured outcomes in the three groups. For demographic data of the participants, ANOVA test was applied and for nominal data chi square test was performed. Numerical data was demonstrated as mean and standard deviation while nominal data was demonstrated as number and percentage. The significance level was set at $\mathrm{P} \leq 0.05$. SPSS statistics version 20 was used for statistical analysis.

\section{Results \\ Demographic data}

There was no significant difference among the demographic data of the participants ( $\mathrm{p}$ value> 0.05 ), as shown in table 1 .

Table 1. Baseline Demographic Characteristics of Subjects.

\begin{tabular}{|c|c|c|c|c|}
\hline & $\begin{array}{l}\text { PUVA } \\
\text { group } \\
(n=18)\end{array}$ & $\begin{array}{l}\text { Iontophoresis } \\
\text { group } \\
(\mathrm{n}=18)\end{array}$ & $\begin{array}{l}\text { Control } \\
\text { group } \\
(\mathbf{n}=\mathbf{2 0})\end{array}$ & p-value \\
\hline & Mean \pm SD & Mean \pm SD & Mean \pm SD & \\
\hline $\begin{array}{c}\text { Age } \\
\text { (years) }\end{array}$ & $14.3 \pm 2.36$ & $14.85 \pm 2.43$ & $15.1 \pm 2.1$ & 0.569 \\
\hline $\begin{array}{l}\text { Sex } \\
\text { (B: G) } \\
\text { (B: G\%) }\end{array}$ & $\begin{array}{c}(8: 10) \\
(44.4: 55.6 \%)\end{array}$ & $\begin{array}{c}(10: 8) \\
(55.6: 44.4 \%)\end{array}$ & $\begin{array}{l}(9: 11) \\
(45: 55 \%)\end{array}$ & 0.750 \\
\hline
\end{tabular}

D: standard deviation. P value: significance level, B: Boy, G: Girl, M: mean, PUVA: psoralen plus ultraviolet $A$, $n$ : number.

\section{POAM scale.}

There was a statistically significant difference between pre and post values of the POAM scale measurement within the three studied groups. (p value< 0.05). Pretreatment there was no significant difference between groups ( $\mathrm{p}$ value> 0.05). Concerning comparisons between groups post treatment, no significant difference was observed between PUVA and Iontophoresis groups $(\mathrm{p}$ value $=0.190)$. Furthermore, a significant difference was noticed between PUVA and control groups favoring PUVA group ( $\mathrm{p}$ value $<$ 0.001). Also, Comparison between the Iontophoresis and control groups POAM scale post mean values revealed a significant difference favoring Iontophoresis group ( $\mathrm{p}$ value $<0.001$ ) as shown in table 2 .

Ultrasonography.

Significant difference was found within the three groups between pre and post mean values concerning ultrasonography ( $\mathrm{p}$ value $<0.05$ ) with a higher mean difference (MD) and narrow confidence interval (CI) 6.94(6-7.85) in the PUVA group. There was no significant difference between groups before the start of the treatment $(p$ value >0.05). Post treatment there was a 
significant difference between PUVA and control group favoring PUVA group ( $\mathrm{p}$ value $<0.001$ ). However, there was no significant difference between PUVA group and Iontophoresis group ( $\mathrm{p}$ value $=0.066$ ). Moreover, there was a significant difference between Iontophoresis and control groups favoring iontophoresis group $(\mathrm{p}$ value $=$ 0.001 ). as shown in table 2 .

Table (2) Outcome Data for POEM Scale and Skin Thickness by Ultrasonography at Base line and after 8 weeks of Intervention( $n=56)$.

\begin{tabular}{|c|c|c|c|c|}
\hline Outcome & $\begin{array}{l}\text { PUVA } \\
\text { group } \\
(n=18) \\
(M \pm S D)\end{array}$ & $\begin{array}{l}\text { Iontophores } \\
\text { is group } \\
(\mathrm{n}=18) \\
(\mathrm{M} \pm \mathrm{SD})\end{array}$ & $\begin{array}{l}\text { Control } \\
\text { Group } \\
(\mathbf{n}=\mathbf{2 0}) \\
(\mathbf{M} \pm \mathbf{S D})\end{array}$ & $\begin{array}{l}\mathbf{P} \\
\text { value }^{*}\end{array}$ \\
\hline \multicolumn{5}{|c|}{ POAM scale } \\
\hline Baseline & $19 \pm 1.7$ & $19.6 \pm 2.3$ & $18.9 \pm 1.7$ & 0.467 \\
\hline $\begin{array}{l}\text { After } \\
\text { treatment }\end{array}$ & $8.4 \pm 2.16$ & $9.25 \pm 1.33$ & $14.77 \pm 2.38$ & $<0.001$ \\
\hline P value ${ }^{\dagger}$ & 0.001 & 0.001 & 0.001 & \\
\hline MD (CI) & $\begin{array}{l}10.6 \\
(9.6-11.6)\end{array}$ & $\begin{array}{l}10.35 \\
(9.4-11.3)\end{array}$ & $\begin{array}{l}4.1 \\
(5.1-3.2)\end{array}$ & \\
\hline \multicolumn{5}{|c|}{ Thickness of the Skin by Ultrasonography } \\
\hline Baseline & $17.26 \pm 2.5$ & $17.52 \pm 2.58$ & $17.2 \pm 2.44$ & 0.890 \\
\hline $\begin{array}{l}\text { After } \\
\text { treatment }\end{array}$ & $10.32 \pm 0.93$ & $11.19 \pm 1.17$ & $12.77 \pm 1.98$ & $<0.001$ \\
\hline P value ${ }^{\dagger}$ & 0.001 & 0.001 & 0.001 & \\
\hline $\operatorname{MD}(\mathrm{CI})$ & $\begin{array}{l}6.94 \\
(6-7.85)\end{array}$ & $\begin{array}{l}6.34 \\
(5.4-7.25)\end{array}$ & $\begin{array}{l}4.38 \\
(3.5-3.25)\end{array}$ & \\
\hline
\end{tabular}

P value ${ }^{\dagger}$ : within group significant level, $P$ value*, MD: Mean difference, CI: confident interval. M: mean, SD: Standard deviation, n: number. PUVA: psoralen plus UVA.

\section{Discussion}

A comparative analysis was performed during the current study to examine the effects of photochemotherapy "bath Psoralen plus UVA" along with traditional medical treatment, tap water iontophoresis with traditional medical treatment and traditional medical treatment only for the management of atopic dermatitis in paediatrics. An eczema severity PEOM scale was chosen as the essential parameter for dermatitis severity. It was revealed that all the three treatment approaches had significant effects in management of atopic dermatitis in children, based on the results of the PEOM scale, and skin thickness measured by ultrasonography. However, the highest improvement in all outcomes was detected in the group received PUVA with traditional medical treatment.

The finding of the current study could be explained by the suppressing effect of Psoralen and UVA on the accelerated DNA synthesis, such as in epidermal cells of patients with psoriasis. In addition, to DNA effect, it up-regulates expression of tumor suppressor gene p53 resulting in apoptosis of keratinocytes. It causes photoisomerization of urocanic acid, which has immuno-suppressive effects via cutaneous cytokine production. PUVA therapy activate keratinocytes synthesize which acts as an inflammatory mediator e.g., interleukin (IL)-1 and TNF-a, suppressing Langerhans cells and thereby induce immunosuppression (20).

Psoralen-UVA Photochemotherapy is generally proved to be effective in treating thicker, solidified lesions of hand and foot psoriasis and eczema, due to its deeper penetration (21).

In accordance with the current study, a randomized, multi-centre study examined efficacy of iontophoresis accompanied with confined psoralen plus ultraviolet A (PUVA) therapy in chronic plantar eczema. It revealed that iontophoresis combined with "puva" was superior to the puva group and the local cortisone group respectively. Eczema score and dermatology life quality index were used as assessment tools (22). Moreover, bath psoralen plus ultraviolet A (PUVA) therapy was found to be beneficial in treating severe cases of atopic dermatitis (23).

Abtahi et al, (24) reported that bath PUVA is a potent and safe modality in the treatment of severe and/or refractory $\mathrm{AD}$ but in contrast to our work, their study was limited to the small sample size and absence of control group.

Although tap water iontophoresis is most commonly used for hyperhidrosis, it has a long and successful history of use in eczema treatment as well (25). It was reported that iontophoresis causes reduction in the substance P. (26), which increased in atopic dermatitis, (27) and it is the most common cause of dyshidrotic palmoplantar eczema (28).

The effect of tap water iontophoresis might be attributed to the disturbance in postsynaptic functional secretion of sweat gland (29) As well, it has been indicated that tap water iontophoresis hinders the work of neuropeptides and cytokines in the sweat glands causing improvement in the dermatitis.

In Japan, three-school tap water bath intervention studies were conducted on children with $\mathrm{AD}$ and reported that bathing notably minimized the symptoms of $\mathrm{AD}$, that was more marked in high sweat volume seasons (30). A study on vesicular palmar eczema, reported that iontophoresis had an advantageous ramification on vesicles and pruritus scores, but not on erythema and scaling scores. The iontophoresis device, which was used daily for 3 weeks, tap water iontophoresis had a 
comprehensible ramification on itching and vesicles of palmar dermatitis (25). Another study has indicated a valuable ramification of it on the recurrence free span in palmoplantar dermatitis (28).

Limitation of the study: The long-term effect of PUVA and tap water iontophoresis on POEM scale and thickness of the skin in AD children was not studied at the current research. Further studies should be conducted to examine the effect of both modalities in different age groups in children. Moreover, further studies are needed to compare between boys and girls.

\section{Conclusion}

Finding of this study revealed that PUVA and tap water iontophoresis proved to be superior to medical therapy, and PUVA was better than tap water iontophoresis but without significant difference for improving skin thickness and POEM scale for atopic dermatitis in children.

\section{Acknowledgments}

The authors would like to express their thanks to all the patients who participated in this work.

\section{Conflict of Interests}

The current study obtained no specific funding as financial support, authorship and/or publication for this work. The investigators also declare no conflicts of interest in preparing this scrutiny.

\section{References}

1. Bieber T. Atopic dermatitis. Ann Dermatol. 2010; 22:125-137.

2. Schneider L, Tilles S, Lio P, Boguniewicz M, Beck L, LeBovidge J, et al. Atopic dermatitis: a practice parameter update 2012. J allergy clin immu, 2013 Feb;131(2):295-9. e1-27.

3. Higaki Y, Kawamoto K, Kamo T, Ueda S, Arikawa $\mathrm{J}$, Kawashima M: Measurement of the impact of atopic dermatitis on patients' quality of life: a cross-sectional and longitudinal questionnaire study using the Japanese version of Skindex-16. J Dermatol 2004; 31: 977-982.

4. Msika P, De Belilovsky C, Piccardi N, Chebassier $\mathrm{N}$, Baudouin C, Chadoutaud B. New emollient with topical corticosteroid-sparing effect in treatment of childhood atopic dermatitis: SCORAD and quality of life improvement. Pediatr dermatol. 2008 Nov;25(6):606-12.

5. Sidbury R, Davis DM, Cohen DE, Cordoro KM, Berger TG, Bergman JN, Chamlin SL, Cooper KD, Feldman SR, Hanifin JM, Krol A. Guidelines of care for the management of atopic dermatitis: section 3. Management and treatment with phototherapy and systemic agents. J Am Acad Dermatol. 2014;71(2):327-49

6. Morison WL, Parrish J, Fitzpatrick TB. Oral psoralen photochemotherapy of atopic eczema. Br J Dermatol. 1978; 98:25-30

7. Pašić A, Čeović R, Lipozenčić J, Husar K, Sušić SM, Skerlev M, Hrsan D. Phototherapy in pediatric patients. Pediatric dermatol. 2003;20(1):71-7.

8. Davis DM, Borok J, Udkoff J, Lio P, Spergel J. Atopic dermatitis: phototherapy and systemic therapy. Semin Cutan Med Surg. 2017;36(3):11823 .

9. Singh P, Maibach HI. Iontophoresis in drug delivery: Basic principles and applications. Crit rev Ther drug 1994;11(2-3):161.

10. Hendricks AJ, Vaughn AR, Clark AK, Yosipovitch G, Shi VY. Sweat mechanisms and dysfunctions in atopic dermatitis. J Dermatoll Sci. 2018 Feb $1 ; 89(2): 105-11$.

11. Kreyden OP. Iontophoresis for palmoplantar hyperhidrosis. J cosmet dermatol. 2004 Dec;3(4):211-4.

12. Charman CR, Venn AJ, Ravenscroft JC, Williams HC. Translating Patient-Oriented Eczema Measure (POEM) scores into clinical practice by suggesting severity strata derived using anchor-based methods. British Journal of Dermatology. 2013 Dec;169(6):1326-32.

13. Polańska A, Dańczak-Pazdrowska A, Silny W, Woźniak A, Maksin K, Jenerowicz D, Janicka-Jedyńska M. Comparison between high-frequency ultrasonography (Dermascan C, version 3) and histopathology in atopic dermatitis. Skin Res Technol. 2013;19(4):432-7.

14. Buys LM. Treatment options for atopic dermatitis. Am fam physician. 2007;75(4):523-8.

15. Eichenfield LF, Tom WL, Berger TG, Krol A, Paller AS, Schwarzenberger K, Bergman JN, Chamlin SL, Cohen DE, Cooper KD, Cordoro KM. Guidelines of care for the management of atopic dermatitis: section 2. Management and treatment of atopic dermatitis with topical therapies. J Am Acad Dermatol. 2014; 71(1):116-32.

16. Young A. Carcinogenicity of UVB phototherapy assessed. Lancet 1995;346: 1431-1432. 14.

17. Morison WL, Baughmann RD, Day RM, et al. Consensus workshop on the toxic effects of longterm PUVA therapy. Arch Dermatol 1998;134:595-598.

18. Dogra S, De D. Phototherapy and photochemotherapy in childhood dermatoses. Indian J Dermatol Venereol Leprol. 2010;76:521-6.

19. Karakoc Y, Aydemir EH, Kalkan MT. Placebo-controlled evaluation of direct electrical current administration for palmoplantar 
hyperhidrosis. International journal of dermatology. $2004 \mathrm{Jul} ; 43(7): 503-5$

20. Patrizi A, Raone B, Ravaioli GM. Management of atopic dermatitis: safety and efficacy of phototherapy. Clin Cosmet Investig Dermatol. 2015;8:511-520.

21. Pugashetti R, Koo J. Phototherapy in pediatric patients: choosing the appropriate treatment option. In Seminars in cutaneous medicine and surgery 2010 (Vol. 29, No. 2, pp. 115-120). WB Saunders.

22. Tupker RA, Coenraads PJ, Zanen P, Schuttelaar ML. Randomized controlled observer-blinded treatment of chronic foot eczema with iontophoresis and bath-PUVA. Acta dermatovenereologica. 2013;93(4):456-60.

23. De Kort WJ, Van Weelden H. Bath psoralen-ultraviolet A therapy in atopic eczema. $\mathbf{J}$ Euro Acad Dermatol Venereol. 2000 May;14(3):172-4.

24. Abtahi S, Seirafi H, Balighi K, Ehsani AH, Farnaghi F, Mobasher P. Psoralen and UltraViolet A in Atopic Dermatitis. J Skin Stem Cell. 2017 Jun;4(2).

25. Odia S, Vocks E, Rakosi J, Ring J. Successful treatment of dyshidrotic hand eczema using tap water inotophoresis with pulsed direct current. Acta Derm Venereol 1996; 76: 472-474.

26. Wollina U, Uhleman C, Elstermann D, Ko“ ber L, Barta U. Therapie der Hyperhidrosis mittels Leitungswasseriontophorese. Positive Effekte auf Abheilungszeit und Rezidivfreiheit bei Hand-FussEkzemen. Hautarzt 2000; 49: 109 - 113.

27. Ostlere LS, Cowen T, Rustin MH. Neuropeptides in the skin of patients with atopic dermatitis. Clin experiment dermatol. 1995;20(6):462-7.

28. Wollina U, Karamfilov T. Adjuvant botulinum toxin A in dyshidrotic hand eczema: a controlled prospective pilot study with left-right comparison. J Euro Acad Dermatol Venereol. 2002;16(1):40-2.

29. Reinauer S, Neusser A, Ho"lzle E. Iontophoresis with alternating current and direct current offset (AC/DC iontophoresis): a new approach for the treatment of hyperhidrosis. Br J Dermatol 1993; 129: $166-169$.

30. Murota H, Takahashi A, Nishioka $M$ et al. Showering reduces atopic dermatitis in elementary school students. Eur J Dermatol 2010; 20: 410-411. 